\title{
Trends in the development of composite reinforced concrete structures of pedestrian aboveground overpasses
}

\author{
Valery Eremeev ${ }^{2[0000-0002-2506-9042]}$, Gennady Shmelev ${ }^{10000-0001-6472-9413]}$, Pavel Eremeev 1[0000-0002-8202-5732]*, \\ and Daniil Eremeev ${ }^{10000-0002-7883-1264]}$
}

${ }^{1}$ Kazan State University of Architecture and Engineering, 420043 Kazan, Russia

${ }^{2}$ JSC Spetsremproekt, 420097 Kazan, Russia

\begin{abstract}
Pedestrian bridges are an important part of the urban infrastructure that ensures the safety and comfort of pedestrians. They have a number of distinctive features compared to road bridges. Also, the pedestrian load itself has a significant dynamic component, which can lead to the occurrence of resonant phenomena. Composite reinforced concrete bridges are widely used among the road bridges. This is due to the possibility of including the roadway structure in the act, which increases the load-bearing capacity and reliability of the structure. The same advantages are typical for pedestrian aboveground overpasses. However, pedestrian bridges have a number of features that affect the operation of the composite reinforced concrete structure. It is well-known that the difference between bending structures in civil construction and bending structures in bridge and road construction is the ratio of the rigidness of the concrete and steel parts. The load on pedestrian aboveground overpasses is similar to the temporary load in civil buildings, adjusted for a large dynamic component. But at the same time, the spans of pedestrian aboveground overpasses are similar to the spans of road bridges. In this article, the prospects for the development of composite reinforced concrete structures of pedestrian overpasses are reviewed.
\end{abstract}

Keywords. Pedestrian overpasses, Development prospects, Trends in the development, Composite reinforced concrete structures.

\section{Introduction}

Pedestrian bridges are an important part of the urban infrastructure that ensures the safety and comfort of pedestrians. They have a number of distinctive features compared to road bridges. For example, the structure of a pedestrian overpass takes up a relatively small pedestrian load, with significant spans, which leads to high slenderness ratio. Also, the pedestrian load itself has a significant dynamic component, which can lead to the occurrence of resonant phenomena [1-6]. Accordingly, pedestrian overpasses should provide dynamic pedestrian comfort [7-12].

\footnotetext{
*Corresponding author: pavil-66@inbox.ru
} 
Pedestrian bridges should also be constructed in such way to allow vehicles to pass under them if they are located above the roadway.

Composite reinforced concrete bridges are widely used among the road bridges. This is due to the possibility of including the roadway structure in the act, which increases the loadbearing capacity and reliability of the structure. The same advantages are typical for pedestrian aboveground overpasses.

However, pedestrian bridges have a number of features that affect the operation of the composite reinforced concrete structure. It is well-known that the difference between bending structures in civil construction and bending structures in bridge and road construction is the ratio of the rigidness of the concrete and steel parts. The load on pedestrian aboveground overpasses is similar to the temporary load in civil buildings, adjusted for a large dynamic component. But at the same time, the spans of pedestrian aboveground overpasses are similar to the spans of road bridges. As the result, it can be assumed that the optimal ratio of concrete and steel parts in pedestrian overpasses will differ from the ratio in composite reinforced concrete structures of civil and bridge construction. In this article, the prospects for the development of composite reinforced concrete structures of pedestrian overpasses are reviewed.

\section{Materials and methods}

The prospects for the development of composite reinforced concrete structures of pedestrian overpasses are similar to the prospects for the development of composite reinforced concrete structures in general, taking into account some distinctive features. In this article, the following development prospects will be considered:

1. Development of shear connectors;

2. Development of industrial composite reinforced concrete structures;

3. Application of new materials;

4. Development of multi-profile composite reinforced concrete columns.

\subsection{Development of shear connectors}

The connectors are divided into rigid, flexible and combined. In addition to traditional connectors, such as cylindrical flexible connectors, dowel strips connectors have become widespread [13-18].
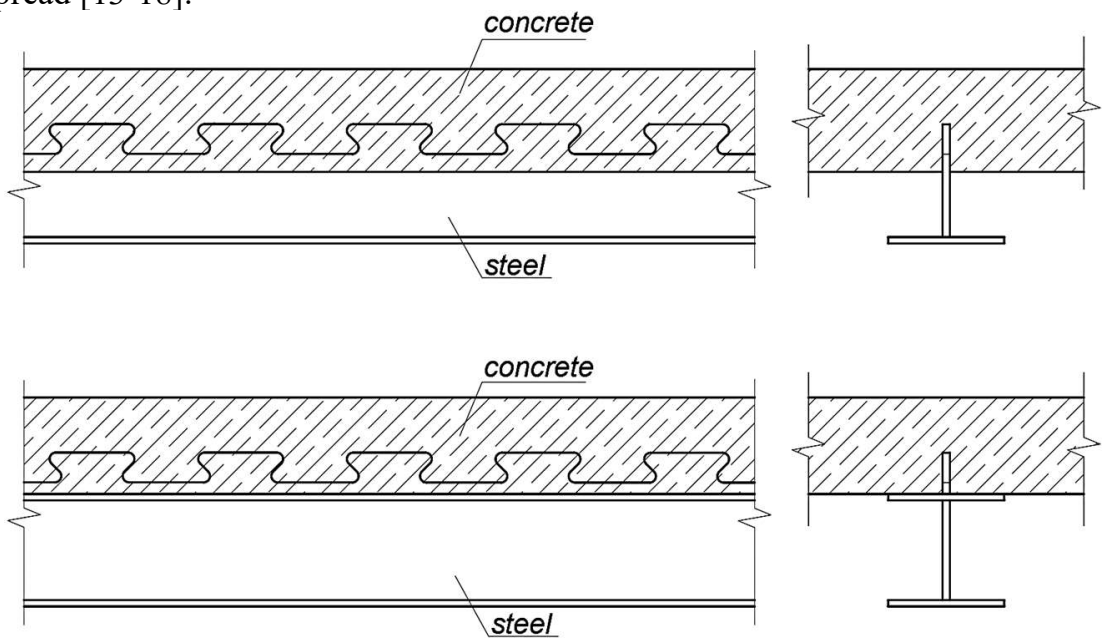

Fig. 1. Dowel strips connectors. 
Their special feature is the reduced labor intensity on the construction site, as they can be welded on the I-beam shelf at the factory or obtained by cutting the part of the $T$-beam. Such connectors have become widespread in both bridge and civil construction. It can be assumed that in pedestrian overpasses, such connectors will have their own characteristics associated with the presence of a dynamic component of the load.

There is a study [19] in which, in order to improve the technical and economic indicators, demountable bolt connectors were developed that can be reused after disassembling the primary structure. Within the area of pedestrian overpasses, such structures are of interest from the point of view of the possibility of their use for the construction of temporary structures. In this case, additional studies are needed to study the influence of the dynamic component of the pedestrian load on the technical state of the connectors (fig. 1).

\subsection{Development of industrial composite reinforced concrete structures}

The use of industrial composite reinforced concrete structures has a number of advantages, such as the ability to ensure the best quality of construction, single-stage operation and speed of installation. These structures may be of interest in terms of the possibility of use them in pedestrian overpasses, but it is not known how much the stress and strains in the structure will decrease. There is also insufficient data on the impact of the dynamic component of the load on the state of the connectors (fig.2).

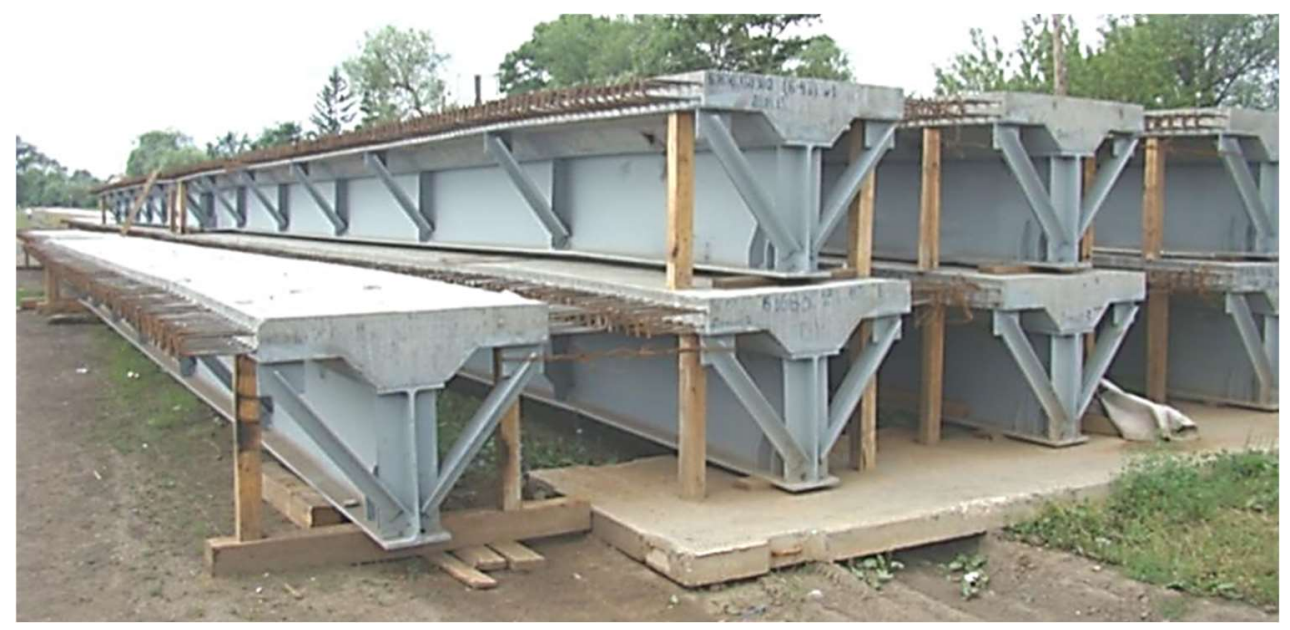

Fig. 2. Production of single-stage operation beams.

\subsection{Development of industrial composite reinforced concrete structures}

Concrete and steel are traditionally used as materials for the composite cross-section of the bent elements. However, research on the replacement of steel elements with polymer composite ones has been developed [20]. The use of new materials in pedestrian overpasses is connected to a relatively low load from pedestrians, in comparison with road bridges.

The use of composite materials for a road bridge [20] illustrated the need to ensure the elastic horizontal and vertical operation of the connectors. Further research is needed to determine this need for pedestrian bridges (fig. 3). 


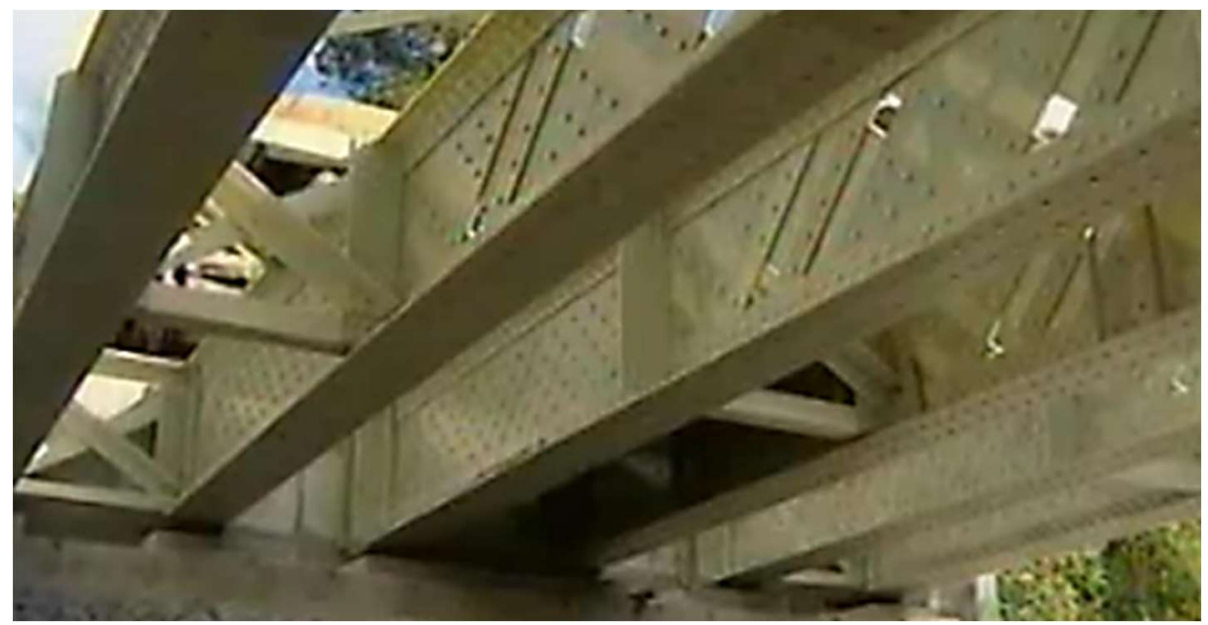

Fig. 3. Fragment of a road bridge superstructure made of composite polymer material.

\subsection{Development of multi-profile composite reinforced concrete columns}

The features of the columns of pedestrian overpasses include the possibility of impact from the vehicle. To ensure safety in this case, it is of interest to study the development of composite reinforced concrete columns consisting of several non-directly connected steel elements [21-25]. Studies are required to study the failure of one of the steel elements due to impact and to determine the load-bearing capacity in this case (fig. 4).

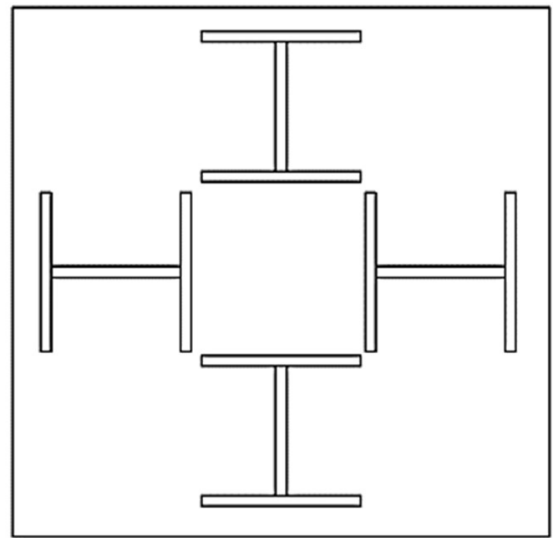

Fig. 4. Diagram of a multi-profile composite reinforced concrete column of 4 I-beams.

\section{Results and discussion}

According to the results of the work, the following prospects for the development of composite reinforced concrete structures of pedestrian overpasses were identified:

1. The study of shear connectors traditionally occupies an important place in the study of composite reinforced concrete structures, since it is often the shear strength that provides the load-bearing capacity and reliability of the structure as a whole. Studies of the connectors of composite reinforced concrete structures generally correspond to pedestrian overpasses, but studies on adaptation are required, taking into account the distinctive features. 
2. Industrial construction has prospects in the construction of pedestrian overpasses, but in order to determine the feasibility, studies are required to determine the benefits.

3. The development of industrial capacities of plants for the production of composite polymer materials has allowed them to be used in a greater number of structures, including pedestrian overpasses. However, further research is needed for wider distribution.

4. Aboveground pedestrian overpasses are usually arranged in places of heavy traffic, which entails the risk of a vehicle hitting the column. One of the solutions can be the use of a multi-profile composite reinforced concrete column, considered in the article.

\section{Conclusions}

The considered trends and prospects for the development of composite reinforced concrete structures of pedestrian aboveground overpasses correspond to the development of composite reinforced concrete structures in general, but distinctive features, such as the ratio of concrete and steel stiffness, as well as the presence of a dynamic component of the load from pedestrians, lead to the need for additional research. The authors of the article plan to conduct further research taking into account the prospects and trends of development discussed in the article.

\section{References}

1. M. Bocian, J.H.G. Macdonald, J.F. Burn. Biomechanically Inspired Modeling of Pedestrian-Induced Vertical Self-Excited Forces, J. Bridg. Eng. 18 (12), 1336-1346 (2013). DOI: 10.1061/(asce)be.1943-5592.0000490.

2. S.P. Carroll, J.S. Owen, M.F.M. Hussein. Modelling crowd-bridge dynamic interaction with a discretely defined crowd, J. Sound Vib. 331 (11), 2685-2709 (2012). DOI: 10.1016/j.jsv.2012.01.025.

3. J.W. Qin, S.S. Law, Q.S. Yang, N. Yang. Pedestrian-bridge dynamic interaction, including human participation, J. Sound Vib. 332 (4), 1107-1124 (2013). DOI: 10.1016/j.jsv.2012.09.021.

4. J. Hu, X. Bian, J. Jiang. Critical Velocity of High-speed Train Running on Soft Soil and Induced Dynamic Soil Response, in Procedia Engineering 143, 1034-1042 (2016). DOI: 10.1016/j.proeng.2016.06.102.

5. E. Ntotsios. Modelling of Train Induced Vibration, in Stephenson Conference Research for Railways 2015, 2015-April, 153-162 (2015).

6. E. Ahmadi, C. Caprani, S. Živanović, A. Heidarpour. Vertical ground reaction forces on rigid and vibrating surfaces for vibration serviceability assessment of structures, Eng. Struct. 172, 723-738 (2018). DOI: 10.1016/j.engstruct.2018.06.059.

7. S. Qin, Y.L. Zhou, J. Kang. Footbridge Serviceability Analysis. From System Identification to Tuned Mass Damper Implementation, KSCE J. Civ. Eng. 23 (2), 754762 (2019). DOI: 10.1007/s12205-018-0985-7.

8. D. Wang, C. Wu, Y. Zhang, S. Li. Study on vertical vibration control of long-span steel footbridge with tuned mass dampers under pedestrian excitation, J. Constr. Steel Res. 154, 84-98 (2019). DOI: 10.1016/j.jcsr.2018.11.021.

9. L.F.F. Miguel, L.F. Miguel, R.H. Lopez. A firefly algorithm for the design of force and placement of friction dampers for control of man-induced vibrations in footbridges, Optim. Eng. 16 (3), 633-661 (2015). DOI: 10.1007/s11081-014-9269-3.

10. H. Bachmann, and W. Ammann. Vibrations in structures induced by man and machines. Structural Engineering Document 3, International Association for Bridge and Structural Engineering, Zürich 2 (A), (1987). 
11. D.E. Newland. Pedestrian excitation of bridges, Proc. Inst. Mech. Eng. Part C J. Mech. Eng. Sci. 218 (5), 477-492 (2004). DOI: 10.1243/095440604323052274.

12. Y. Fujino, B.M. Pacheco, S.-I. Nakamura, P. Warnitchai. Synchronization of human walking observed during lateral vibration of a congested pedestrian bridge, Earthquake Engng Struct. Dynamics 22, 741-758 (1993). DOI: 10.1002/eqe.4290220902.

13. G. Seidl, W. Lorenc. Innovative solutions in bridge construction with composite dowel strips, Stahlbau 87 (6), 547-554 (2018). DOI: 10.1002/stab.201810617.

14. M. Classen, J. Hegger. Pry-out of composite dowels in cracked concrete - Experimental investigation, Stahlbau 86 (3), 256-268 (2017). DOI: 10.1002/stab.201710470.

15. J. Springer, H. Reuke, K. Wolters, M. Kopp. Special features of the composite structure of the Car Park Coulinstraße in Wiesbaden, Germany, Stahlbau 87 (7), 695-703 (2018). DOI: $10.1002 /$ stab.201810625.

16. M. Kożuch, W. Lorenc. The behaviour of clothoid-shaped composite dowels: Experimental and numerical investigations, J. Constr. Steel Res. 167 (2020). DOI: 10.1016/j.jcsr.2020.105962.

17. P. Lacki, P. Kasza, and K. Adamus. Optimization of composite dowels shape in steelconcrete composite floor, Compos. Struct. 222, (2019). DOI: 10.1016/j.compstruct.2019.110902.

18. M. Kożuch, W. Lorenc. Stress concentration factors of shear connection by composite dowels with MCL shape, Arch. Civ. Mech. Eng., 19 (1), 32-46 (2019). DOI: 10.1016/ j.acme.2018.08.006.

19. A. Kozma, C. Odenbreit, M.V. Braun, M. Veljkovic, M.P. Nijgh. Push-out tests on demountable shear connectors of steel-concrete composite structures, Structures 21, 4554 (2019). DOI: 10.1016/j.istruc.2019.05.011.

20. A.N. Ivanov, A.N. Yashnov. Improving the construction and calculation methods of span structures of bridges with load-bearing elements made of composite materials, Scientific problems of transport in Siberia and the Far East 1-2, 142-146 (2014).

21. T. Bogdan, M. Chrzanowski, C. Odenbreit. Mega columns with several reinforced steel profiles - Experimental and numerical investigations, Structures 21, 3-21 (2019). DOI: 10.1016/j.istruc.2019.06.024.

22. G. Ranzi, A. Zona. A steel-concrete composite beam model with partial interaction including the shear deformability of the steel component, Eng. Struct. 29 (11), 3026-3041 (2007). DOI: 10.1016/j.engstruct.2007.02.007.

23. G. Ranzi, A. Zona. Finite element models for nonlinear analysis of steelconcrete composite beams with partial interaction in combined bending and shear, Finite Elem. Anal. Des. 43 (2), 98-118 (2011). DOI: 10.1016/j.finel.2010.09.006.

24. C.G. Chiorean, S.M. Buru. Practical nonlinear inelastic analysis method of composite steel-concrete beams with partial composite action, Eng. Struct. 134 (1), 74-106 (2017). DOI: 10.1016/j.engstruct.2016.12.017.

25. K. Misiurek, P. Śniady. Vibrations of sandwich beam due to a moving force, Compos. Struct. 104, 85-93 (2013). DOI: 10.1016/j.compstruct.2013.04.007. 